Case Report

\title{
Phenotypic Diversity of 15q11.2 BP1-BP2 Deletion in Three Korean Families with Development Delay and/or Intellectual Disability: A Case Series and Literature Review
}

\author{
Ji Yoon Han ${ }^{1}$ and Joonhong Park $2,3, * \mathbb{D}$ \\ 1 Department of Pediatrics, College of Medicine, The Catholic University of Korea, Seoul 06591, Korea; \\ han024@catholic.ac.kr \\ 2 Department of Laboratory Medicine, Jeonbuk National University Medical School and Hospital, \\ Jeonju 54907, Korea \\ 3 Research Institute of Clinical Medicine of Jeonbuk National University-Biomedical Research Institute of \\ Jeonbuk National University Hospital, Jeonju 54907, Korea \\ * Correspondence: miziro@jbnu.ac.kr; Tel.: +82-63-250-1218
}

check for

updates

Citation: Han, J.Y.; Park, J. Phenotypic Diversity of $15 \mathrm{q} 11.2$ BP1-BP2 Deletion in Three Korean Families with Development Delay and/or Intellectual Disability: A Case Series and Literature Review. Diagnostics 2021, 11, 722. https:// doi.org/10.3390/diagnostics11040722

Academic Editor: Ineke Van Der Burgt

Received: 1 March 2021

Accepted: 16 April 2021

Published: 19 April 2021

Publisher's Note: MDPI stays neutral with regard to jurisdictional claims in published maps and institutional affiliations.

Copyright: (c) 2021 by the authors. Licensee MDPI, Basel, Switzerland. This article is an open access article distributed under the terms and conditions of the Creative Commons Attribution (CC BY) license (https:// creativecommons.org/licenses/by/ $4.0 /)$.

\begin{abstract}
The 15q11.2 breakpoint (BP) 1-BP2 deletion syndrome is emerging as the most frequent pathogenic copy number variation in humans related to neurodevelopmental diseases, with changes in cognition, behavior, and brain morphology. Previous publications have reported that patients with 15q11.2 BP1-BP2 deletion showed intellectual disability (ID), speech impairment, developmental delay (DD), and/or behavioral problems. We describe three new cases, aged 3 or 6 years old and belonging to three unrelated Korean families, with a 350-kb 15q11.2 BP1-BP2 deletion of four highly conserved genes, namely, the TUBGCP5, CYFIP1, NIPA2, and NIPA1 genes. All of our cases presented with global DD and/or ID, and the severity ranged from mild to severe, but common facial dysmorphism and congenital malformations in previous reports were not characteristic. The 15q11.2 BP1-BP2 deletion was inherited from an unaffected parent in all cases. Our three cases, together with previous findings from the literature review, confirm some of the features earlier reported to be associated with 15q11.2 BP1-BP2 deletion and help to further delineate the phenotype associated with 15q11.2 deletion. Identification of more cases with 15q11.2 BP1-BP2 deletion will allow us to obtain a better understanding of the clinical phenotypes. Further explanation of the functions of the genes within the 15q11.2 BP1-BP2 region is required to resolve the pathogenic effects on neurodevelopment.
\end{abstract}

Keywords: 15q11.2 BP1-BP2 deletion; phenotypic diversity; development delay; intellectual disability; array comparative genomic hybridization

\section{Introduction}

The proximal long arm of chromosome 15 is a region rich in segmental duplications that houses five breakpoints (BPs) for recurrent $15 \mathrm{q}$ copy number variations (CNVs) as defined by non-allelic homologous recombination. Microdeletions extending from BP1 to BP3 (type 1) or from imprinted region BP2 to BP3 (type 2) cause Prader-Willi syndrome/Angelman syndrome (PWS/AS), depending on the parental origin of the deleted allele [1]. The 15q13.3 microdeletion between BP4 and BP5, which constitutes the CHRNA7 gene, causes mild to moderate intellectual disability (ID) associated with epilepsy with various phenotypes [2]. The 15q11.2 BP1-BP2 deletion (Burnside-Butler) syndrome is emerging as the most frequent pathogenic CNV in humans related to neurodevelopmental diseases, with changes in cognition, behavior, and brain morphology [3]. Previous publications have reported that patients with the 15q11.2 BP1-BP2 deletion showed learning disabilities, speech impairment, developmental delay (DD), and/or behavioral problems [4-7]. Due to the various phenotypes, it is difficult to provide genetic counselling to families with the 
15q11.2 BP1-BP2 deletion, particularly before prenatal diagnosis [8]. More than 200 15q11.2 deletion carriers have been described in clinical cases with mild, moderate, and severe neurodevelopmental manifestations as well as impairments, causing physicians to delineate a microdeletion syndrome with considerable variable expressivity [8] and incomplete penetrance [9]. Nevertheless, several patients carried another related genetic alteration and added confusion to genotype-phenotype correlations [7]. In addition, this CNV is frequently inherited from an unaffected parent; thus, the pathogenicity of the 15q11.2 BP1-BP2 deletion seems unclear, leading to its interpretation as a variant of uncertain significance.

In this report, we describe three new cases of 15q11.2 BP1-BP2 deletion of four highly conserved genes, namely, the TUBGCP5, CYFIP1, NIPA2, and NIPA1 genes. All of our cases presented with global DD and/or ID, and the severity ranged from mild to severe, but the common facial dysmorphism and congenital malformations in previous reports were not characteristic.

\section{Materials and Methods}

\subsection{Samples and DNA Extraction}

We evaluated three unrelated cases diagnosed as DD/ID belonging to three different families referred to the Department of Pediatric Neurology, Daejeon St. Mary's Hospital (Daejeon, Korea). Genomic DNA samples were obtained from leukocytes of peripheral blood using a QIAamp DNA Mini Kit (Qiagen GmbH, Hilden, Germany) according to the standard DNA isolation process. Their quantity and quality were estimated using a Qubit 2.0 Fluorometer with the Qubit dsDNA HS Assay kit and the TaqMan RNase P Detection Reagents kit (ThermoFisher Scientific, Waltham, MA, USA), and they were considered appropriate when the genomic DNA concentration was $>10 \mathrm{ng} / \mu \mathrm{L}$.

\subsection{Array Comparative Genomic Hybridization}

To identify the potential genetic cause of DD/ID in the three probands and their family members, array comparative genomic hybridization (CGH) was used to provide candidates for a first-tier clinical diagnostic test. We performed whole-genome screening of chromosomal rearrangements by array CGH using a SurePrint G3 Human CGH + SNP Microarray $4 \times 180 \mathrm{~K}$ (Agilent Technologies, Santa Clara, CA, USA) according to the manufacturer's instructions. All samples were matched with a human genomic DNA reference (Agilent Technologies or Promega, Madison, WI, USA). Data were obtained using the Agilent Feature Extraction software 12.0.2.2 and Agilent CytoGenomics 4.0 and visually assessed using the Agilent Genomic Workbench Software 7.0.4.0 and Agilent CytoGenomics 4.0. CNVs were identified using the ADM-2 algorithm, with filters of a minimal absolute average log ratio of 0.25 as a cut-off, $>5 \mathrm{Mb}$ of copy number neutral loss of heterozygosity regions, and a minimal size of $200 \mathrm{~kb}$ in the region. Genomic positions were mapped using the human genomic reference sequence GRCh37/hg19.

\subsection{Exome Sequencing}

In our three families, all of the probands were symptomatic, whereas their parents had no symptoms. If both parents are carriers of an autosomal recessive inheritance, this phenomenon could explain why they had an affected child. Thus, trio exome sequencing was performed to resolve this situation using the Agilent SureSelect XT Human All Exon kit v5 (Agilent Technologies, Santa Clara, CA, USA). Paired-end sequencing was conducted on the Illumina HiSeq 2500 system (Illumina, San Diego, CA, USA) to identify the genetic alteration, given the suspicion of neuropsychiatric disorder at the Green Cross Genome (Yongin, Korea). Base calling, alignment, variant calling, annotation, and quality control reporting were performed using a GATK Best Practices workflow for germline short variant discovery (https:/ / gatk.broadinstitute.org/hc/en-us; accessed on 6 September 2020). The interpretation of sequence variants was manually reviewed by medical laboratory geneticists according to standards and guidelines from the Joint Consensus Recommendation of the American College of Medical Genetics and Genomics and the Association 
for Molecular Pathology [10]. Nucleotide changes that pass the filtering criteria are as follows: Phred quality score $>20$, no Fisher strand bias, read depth $>30 \times$, allele frequency $<0.1 \%$, and non-synonymous substitution or indel occurred as compound heterozygous or homozygous state in coding region and exon-intron boundaries.

\section{Case Presentation}

We identified the 15q11.2 BP1-BP2 deletion in children from three unrelated Korean families, including two females and one male. We performed careful etiologic investigations of laboratory studies, and all parameters were within the normal range in all three cases. The laboratory studies included complete blood counts, electrolytes, thyroid function tests, lactate/pyruvate, arterial blood gases, plasma amino acid, urine organic acids, and carnitine profiles, and radiologic tests were conducted, including chest and spine X-rays. A length mutation analysis for FMR1 (CGG)n triplet repeat status was conducted using AmplideX FMR1 PCR reagents (Asuragen, Austin, TX, USA) and showed normal results (<45 repeats). Chromosomal analysis revealed a normal karyotype. The results of brain magnetic resonance imaging, auditory, and ophthalmological tests for our cases were normal.

Case A-II-3 (upper panel in Figure 1), a female diagnosed with DD at 3 years of age with DD, was referred for genetic diagnosis. She is a third child of non-consanguineous parents, and there is no family history of neurodevelopmental disorders. She was born via normal vaginal delivery at 39 weeks following an uneventful pregnancy. During infancy, she showed mild hypotonia and gross motor delay. She could control her head at 4 months, sit alone at 9 months, and walked at about 18 months. Her speech was delayed, and she could not speak in full sentences before she was 3 years old. She could speak only a few words at 40 months. At the age of 5 years, she had mild ID with an intelligence quotient (IQ) of 60 and attended an elementary school with additional specialized education at 7 years old. She had neither facial dysmorphism nor skeletal abnormalities. Her body weight was $34 \mathrm{~kg}$ (over 97th percentile), height was $119 \mathrm{~cm}$ (75th percentile), and head circumference was $52 \mathrm{~cm}$ (75th percentile). Her body mass index was 24 (over 97th percentile) and indicated obesity. The girl inherited the 15q11.2 BP1-BP2 deletion from her unaffected father. Her siblings have not been investigated.

Case B-II-1 (upper panel in Figure 1), a 6-year-old female with DD, was referred for genetic diagnosis. She is a first child of non-consanguineous parents, and there is no family history of neurodevelopmental disorders. The pregnancy was uneventful, with normal fetal movements. She was born via normal vaginal delivery at 40 weeks, and her birth weight was $3.5 \mathrm{~kg}$. During infancy, early signs of developmental delay were noticed by the parents. She could roll over at 6 months and crawled at 14 months. She experienced unprovoked generalized tonic-clonic seizures at 6 months, and treatment with valproic acid was administrated for 1 year. She spoke a single word, "Mama", at 22 months, and ten or more words at 30 months. She ran fairly well, stooped without bumping into things or falling at 30 months, and walked downstairs alone at 36 months. We examined her using the Bayley scale of infant and toddler development, third edition (Bayley-III), at the age of 48 months and found global DD (cognitive, motor, and language developmental ages: 13-18 months, 23-32 months, and 16-20 months, respectively). She formed sentences that were two words long at age 6 . Formal psychometric tests at 6 years of age revealed an IQ of 45 , and she attends a specialized primary school. She had no facial dysmorphism and showed a normal growth pattern. Her body weight was $20 \mathrm{~kg}$ (50th percentile), height was $112 \mathrm{~cm}$ (25th percentile), and head circumference was $52 \mathrm{~cm}$ (75th percentile). The girl inherited the 15q11.2 BP1-BP2 deletion from her unaffected father. Her sister does not have this deletion.

Case C-II-1 (upper panel in Figure 1), a 3-year-old male with DD and congenital agenesis of the radius noted at birth, was referred for genetic diagnosis. The pregnancy was uneventful, and his parents are both healthy and non-consanguineous. During pregnancy, there was no exposure to drugs, alcohol, or tobacco. He was born at $39+5$ weeks 
via normal spontaneous delivery, and his birth weight was $2590 \mathrm{~g}$. After the birth, he revealed congenital agenesis radius and hypoplastic carpal bones of both forearms. He exhibited torticollis, and a neck sonogram identified sternocleidomastoid muscle thickening. An echocardiogram showed a known cause of cardiac murmur and showed an atrial septal defect (type: ostium secundum). The atrial septal defect was closed 4 weeks after the birth Special evaluation for skeletal dysplasia including laboratory tests and imaging was within the normal range. We examined him using the Bayley-III scale at the age of 39 months and found global DD (cognitive, motor, and language developmental ages: 19-22 months, 23-26 months, and 15-19 months, respectively). He had fine motor impairment in throwing a small ball, stacking small blocks, and making a mark on paper with a crayon at 42 months. His body weight was $13.5 \mathrm{~kg}$ (3rd percentile), height was $100 \mathrm{~cm}$ (10 to 25th percentile), and head circumference was $48.5 \mathrm{~cm}$ (10th percentile) at age 4 . He attended additional education programs, including speech therapy, fine motor exercise, and social skill training. The boy inherited the 15q11.2 BP1-BP2 deletion from his unaffected mother. His sister (age of 32 months) also has this deletion, but is phenotypically unaffected (Table 1).
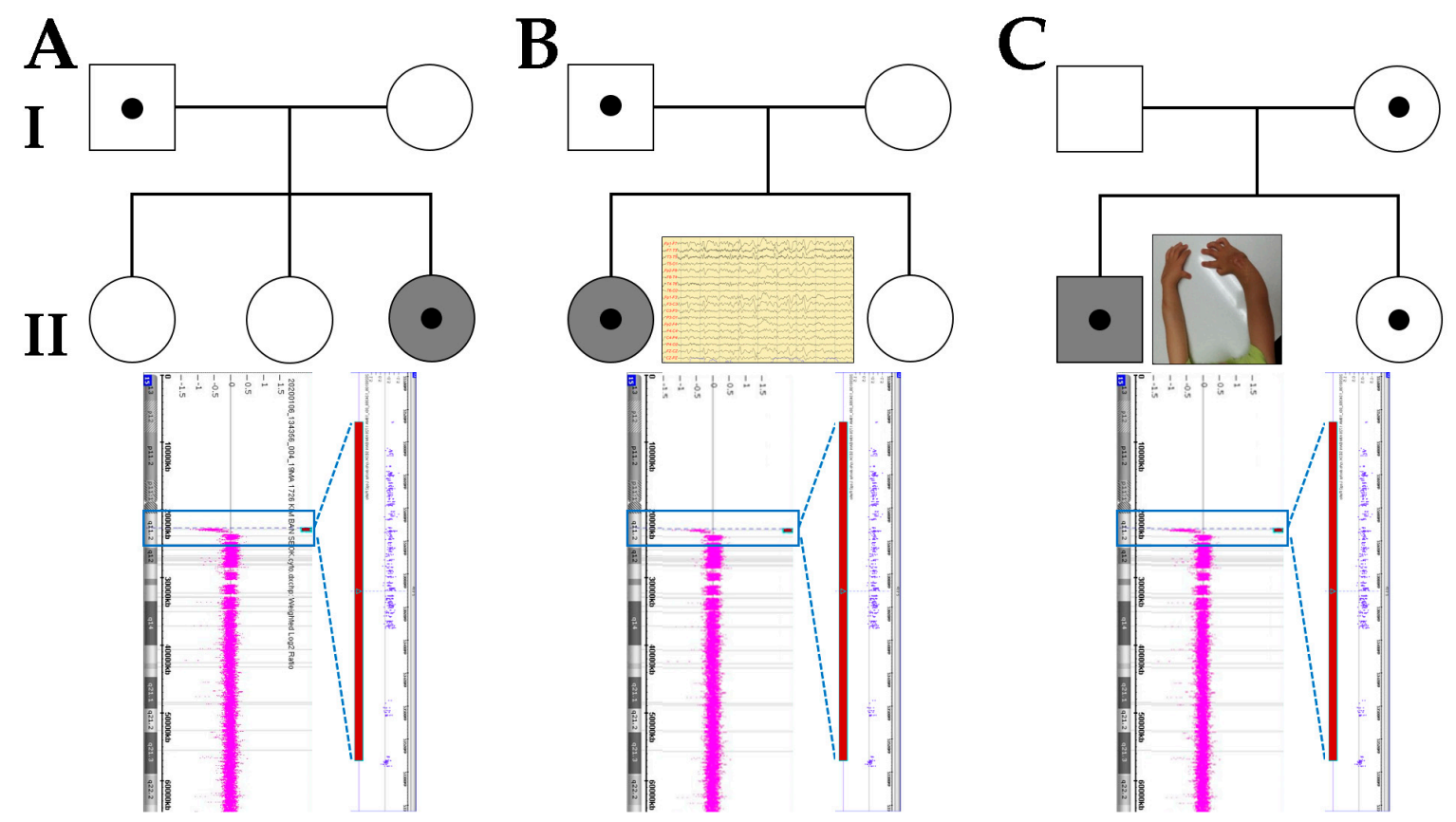

Figure 1. Family pedigree depicting 15q11.2 breakpoint (BP) 1 and BP2 deletion in three unrelated Korean families (A-C) with cases of developmental delay/intellectual disability. The grey symbol indicates an affected individual (upper panel). Array comparative genomic hybridization identified 15q11.2 BP1 and BP2 deletion in each proband (A-II-3, B-II-1, and C-II-1). The array 15q11.2q $\left(22,784,523 \_23,179,948\right) \times 1$ involving the genes TUBGCP5, NIPA1, NIPA2, and CYFIP1 (lower panel). 
Table 1. Comparison of the clinical manifestations between three cases with 15q11.2 breakpoint (BP) 1 and BP2 deletion.

\begin{tabular}{|c|c|c|c|}
\hline Clinical Manifestations & A-II-3 & B-II-1 & C-II-1 \\
\hline $\begin{array}{l}\text { Sex/Age (Year) at } \\
\text { Diagnosis }\end{array}$ & $\mathrm{F} / 3$ & $\mathrm{~F} / 6$ & $\mathrm{M} / 3$ \\
\hline Inheritance & Paternal & Paternal & Maternal \\
\hline Parent Status & Unaffected & Unaffected & Unaffected \\
\hline Height $<-2$ SD & Absent & Absent & Absent \\
\hline Obesity & Present & Absent & Absent \\
\hline \multicolumn{4}{|l|}{ Auxology } \\
\hline IUGR & Absent & Absent & Absent \\
\hline Failure to Thrive & Absent & Absent & Absent \\
\hline Microcephaly & Absent & Absent & Absent \\
\hline \multicolumn{4}{|l|}{ Facial Dysmorphism } \\
\hline High Forehead & Absent & Absent & Absent \\
\hline Hypertelorism & Absent & Absent & Absent \\
\hline Dysplastic Ears & Absent & Absent & Absent \\
\hline Long Philtrum & Absent & Absent & Absent \\
\hline High Arched Palate & Absent & Absent & Absent \\
\hline Micrognathia & Absent & Absent & Absent \\
\hline Cleft Palate/lip & Absent & Absent & Absent \\
\hline \multicolumn{4}{|l|}{ Deformity/Impairments } \\
\hline Brain & Absent & Absent & Absent \\
\hline Heart & Absent & Absent & Absent \\
\hline Vision & Absent & Absent & Absent \\
\hline Hearing & Absent & Absent & Absent \\
\hline \multicolumn{4}{|l|}{ Neurology-Psychiatry } \\
\hline Intellectual Disability & Present & Present & Present \\
\hline Ataxia & Absent & Absent & Absent \\
\hline Seizures & Absent & Present & Absent \\
\hline ASD & Absent & Absent & Absent \\
\hline ADHD & Absent & Absent & Absent \\
\hline OCD & Absent & Absent & Absent \\
\hline $\begin{array}{l}\text { Other Psychobehavioral } \\
\text { Problems }\end{array}$ & Absent & Absent & Absent \\
\hline \multicolumn{4}{|l|}{ Neurodevelopment } \\
\hline Hypotonia & Present & Present & Present \\
\hline $\begin{array}{l}\text { Delayed Motor } \\
\text { Milestones }\end{array}$ & Present & Present & Present \\
\hline Speech Impairment & Present & Present & Present \\
\hline Learning Difficulties & Present & Present & Present \\
\hline
\end{tabular}

M, male; F, female; SD: Standard Deviation; IUGR: intrauterine growth retardation; ASD: autism spectrum disorder; ADHD: attention deficit hyperactivity disorder; OCD: obsessive compulsive disorder.

\section{Results}

Following the genetic analyses, the array CGH identified an approximately $350-\mathrm{kb}$ microdeletion located between BP1 and BP2 in the PWS/AS critical region and involved the same four highly conserved genes, namely, TUBGCP5, NIPA1, NIPA2, and CYFIP1, in all three cases (lower panel in Figure 1). However, there were no likely shared pathogenic candidate variants identified by trio exome sequencing or correlations between genotype and clinical phenotype in any of the three cases with the 15q11.2 BP1-BP2 deletion.

\section{Discussion}

Various mechanisms affect the generation of $\mathrm{CNVs}$, including non-allelic homologous recombination involving low copy DNA repeats, moving element insertions, nonhomologous end connecting, folk stalling, and template switching [11]. The 15q11.2-q13 region is one of the genomic hotspots for CNVs. Literature review $[4-7,12-16]$ of the clinical characteristics and frequencies in 141 reported cases with 15q11.2 breakpoint (BP) 1 and 
BP2 deletion is illustrated in Figure 2. Patients with a 15q11.2 BP1-BP2 deletion show very different clinical manifestations. Particularly, most cases with the 15q11.2 BP1-BP2 deletion are found at under 18 years of age and show some degree of DD/ID or neuropsychiatric problems. DD/ID were significantly more prevalent in a 15q11.2 BP1-BP2 deletion cohort than in a non-deleted control cohort [17]. Additionally, children with the 15q11.2 BP1-BP2 deletion showed behavioral problems, including attention deficit hyperactivity disorder (ADHD), autism spectrum disorder, obsessive compulsive disorder (OCD), and other psychiatric problems, at a proportion of $70 \%[18,19]$. Seizures were noted in $20 \%$ of the patients and associated malformation of the brain was noted in 35\%. Additionally, 15q11.2 BP1-BP2 deletion affects the brain structure; therefore, some patients have presented with psychosis or schizophrenia [12,20]. Dysmorphic features were reported in 30 to 50\% of the patients and were quite varied, including dysmorphic ear, hypertelorism, high arched palate, and/or micrognathia $[13,14]$. However, a review of the literature indicated that $43 \%$ of these individuals had abnormal brain imaging such as magnetic resonance imaging and computed tomography and electroencephalography, with common clinical features of seizures or epilepsy $(26 \%)$ and ataxia or coordination problems [8,15].

The clinical importance of a pure 15q11.2 BP1-BP2 deletion has been argued. Jønch, A.E., and colleagues recommended that the deletion should be classified as pathogenic of a mild effect size because it explains only a small proportion of the phenotypic variance in carriers [21]. On the contrary, 15q11.2 BP1-BP2 structural variation is associated with cognition and brain morphology, with deletion carriers being particularly affected. The pattern of results fits with the known molecular functions of genes in the 15q11.2 BP1-BP2 region and suggests a contribution of these genes to the association of this CNV with neurodevelopmental disorders [22]. In this report, our cases showed a pathological nature, although there was, apparently, an incomplete penetrance. These parents were completely normal from birth to adolescence and showed no learning difficulties, no facial dysmorphic features, nor any neurodevelopmental disabilities. However, all of our patients showed global DD and/or ID, but the severity ranged from mild to severe, and the common facial dysmorphism and congenital malformations in previous reports were not characteristic of our cases. All of the patients showed mild hypotonia and gross motor delay during infancy, after which, with age, motor delay reached the normal range at around 3 years of age. However, this phenomenon is not severe compared with PWS patients. One patient (B-II-1) diagnosed with infantile epilepsy was treated with anti-seizure medication. In epilepsy during infantile period, nearly $40 \%$ of cases are known to be due to genetic factors [23]. Chromosomal imbalances or gene mutations that are associated with ion channels, including SCN1A, SCN2A, SCN8A, KCNT1, KCNQ2, and FOXG1, could lead to seizures. Patients with the 15q11.2 BP1-BP2 deletion had uncommon non-neurological manifestations that included esophageal atresia, cataracts, tracheoesophageal fistula, and congenital arthrogryposis $[16,24,25]$. We described the first non-neurological presentation of congenital absence of the radius, which helps us understand more expanded features. Hypoplasia or aplasia of the radius were related to some genetic causes that participate in the early phases of skeletal patterning or upper limb growth [26]. About half of radial disorders have a Mendelian inheritance, whereas the remaining half occur sporadically, with no identified genes [27]. All patients with a Mendelian inheritance have syndromic forms, such as Holt-Oram syndrome, Fanconi anemia, platelet deficiency, and Okihiro syndrome, and these are associated with genetic causes such as trisomy 18, 13, HOX, WNT, and TBX [28]. The patient (C-II-1) with congenital agenesis of the radius could be interconnected with neurological dysfunction related to disturbed genes located on 15q11.2 BP1-BP2 and may be considered an extension of the clinical phenotypes. In this study, we performed trio exome sequencing to identify same candidate variants associated with DD/ID, dysplasia of radius, or epilepsy. However, no likely identical pathogenic variants were detected in all three cases, even though we attempted to explain the fact that the patients have different severities and despite having the same genetic cause. Several reports have highlighted the pathological nature of $15 q 11.2$ deletion, although there is 
obviously an incomplete penetrance $[5,8,9,29]$. Additionally, we suggested that $15 \mathrm{p} 11.2$ can be a possible genetic cause of neurodevelopmental delay and other combined features.

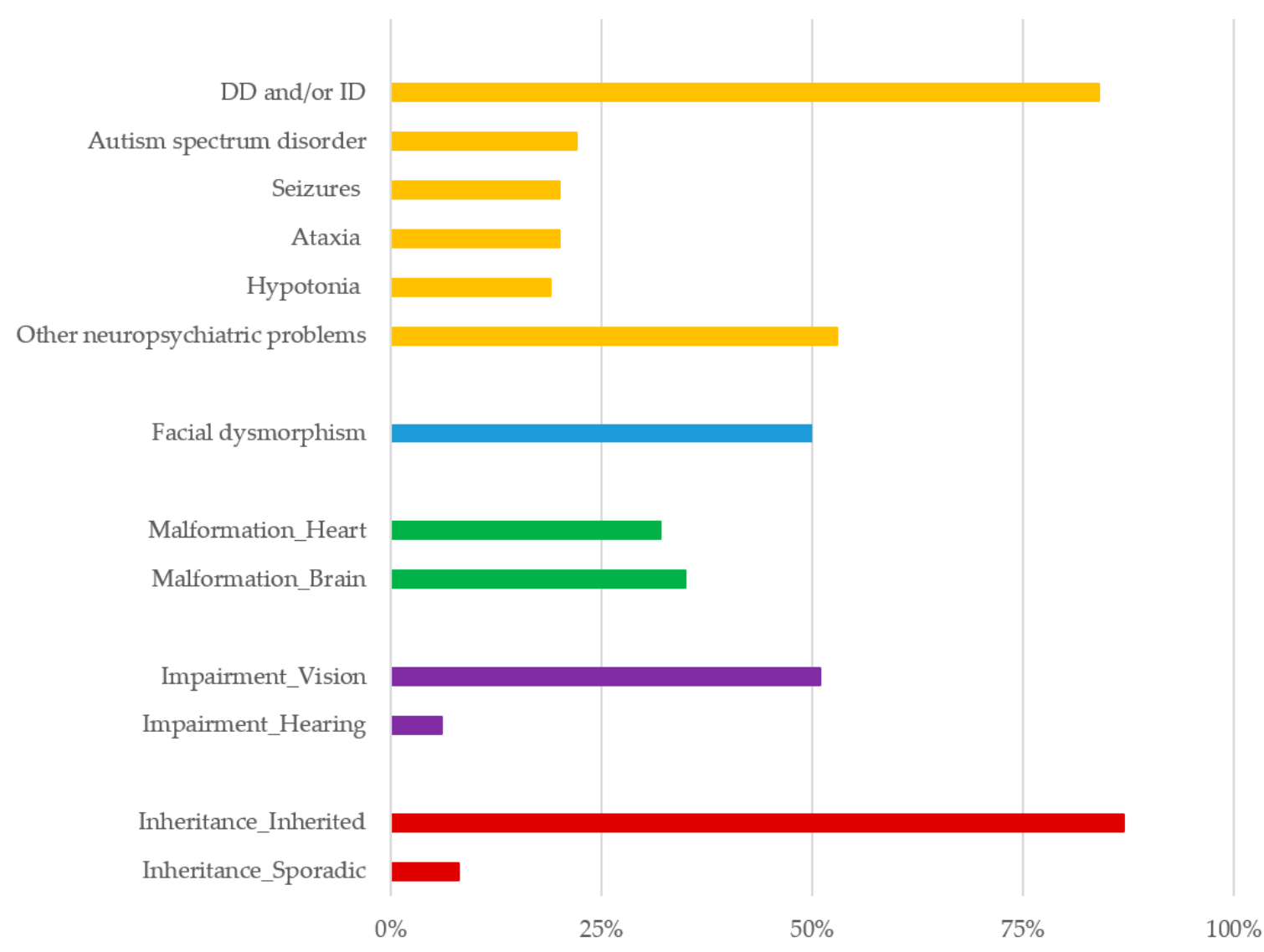

Figure 2. Literature review of the clinical characteristics and frequencies in 141 reported cases with 15q11.2 breakpoint (BP) 1 and BP2 deletion [4-7,12-16]. DD, developmental delay; ID, intellectual disability.

The 15q11.2 BP1-BP2 region showed incomplete penetrance; low penetrance of pathogenicity has been estimated at $10.4 \%$ [9]. All of our cases were inherited from unaffected parents, and penetrance was low in each family. Several hypotheses exist for the incomplete penetrance and different expressivity noted in 15q11.2 BP1-BP2 deletion [5]. A parent or their offspring may be mildly affected and not explore medical consideration. Unequal parental expression of one or more genes can cause specific phenotypes. Incomplete penetrance and differences of expression require further assessment and research. Parent-of-origin effects of the 15q11.2 BP1-BP2 deletion are related to phenotypic differences in clinical features in individuals carrying this deletion. Sex-based differences were observed, such as macrocephaly, epilepsy, and autism spectrum disorder seen in maternal deletions and congenital heart disease, and abnormal muscular phenotypes seen in paternal deletions [29]. The inheritance pattern of our three families does not indicate suspicious genomic imprinting according to the sex of the parent and parent-specific expression. The 15q11.2 BP1-BP2 deletion included four genes, namely, TUBGCP5, CYFIP1, NIPA1, and NIPA2, and these genes are not related to imprinting mechanisms.

These four genes located on the 15q11.2 BP1-BP2 region are highly conserved (Figure 3). When these genes are disturbed, various neuropsychiatric problems seem to occur. Tubulin complex-associated protein 5 (TUBGCP5) encodes the gamma-tubulin complex component 5 that is part of the gamma-tubulin complex, which is necessary for microtubule nucleation at the centrosome $[30,31]$. TUBGCP5 is dominantly expressed in nuclei of the sub-thalamic areas, which have been related to ADHD and OCD [32]. The cytoplasmic FMRP interacting protein 1 (CYFIP1) gene encodes a protein that regulates multiple actions in the cell, 
including organization of the actin cytoskeleton, maturation, and stabilization of dendritic spines $[33,34]$. CYFIP1 has been shown to interact with ras-related C3 botulinum toxin substrate 1 (RAC1), which is expressed in the development and maintenance of dendritic fine structures. CYFIP1/2 is present in synaptic extracts [33]. It can affect various neurodevelopmental pathways, and a large chromosomal deletion including this gene caused dysregulation that raised risk of schizophrenia and seizures in patients [35]. Non-imprinted in PWS/AS region 1 (NIPA1) encodes a magnesium transporter that confers with early endosomes and the cell surface in neurons and epithelial cells [36]. This protein may play a critical role in nervous system development and maintenance. Gain-of-function mutations of this gene have been associated with autosomal dominant spastic paraplegia $6[37,38]$. Two of the four genes (i.e., NIPA1 and NIPA2) are expressed in the brain and encode magnesium transporters. Anecdotally, parents have administered magnesium supplements to their children with the 15q11.2 BP1-BP2 deletion and have observed improvements in behavior and clinical presentation [39]. Some reports identified an association pending confirmation about a variant in the NIPA2 gene in patients with childhood absence seizures or generalized epilepsy $[40,41]$. Recently, in the results of in silico analyses of the functions and interactions of these four protein-coding genes in this region, all four genes were associated with up to three-fourths of ten overlapping neurodevelopmental disorders and were deleted in this most prevalently known pathogenic copy number variation, now recognized among humans with these clinical findings [3]. Recent studies introduced polygenic risk scores for neurodevelopmental disorders and explained the genetic correlation between DD/ID and autistic features [42,43]. Future studies delineating the phenotype associated with 15q11.2 deletion are needed to establish genetic liabilities of the 15q11.2 BP1-BP2 region for neurodevelopmental problems - for instance, quantitative PCR analysis or gene dosage tests such as multiplex ligation-dependent probe amplification of the deleted genes to understand possible differences that might justify the phenotype, or others. Our study had the limitation of a small number of cases; therefore, further phenotype studies with larger cohorts are required.

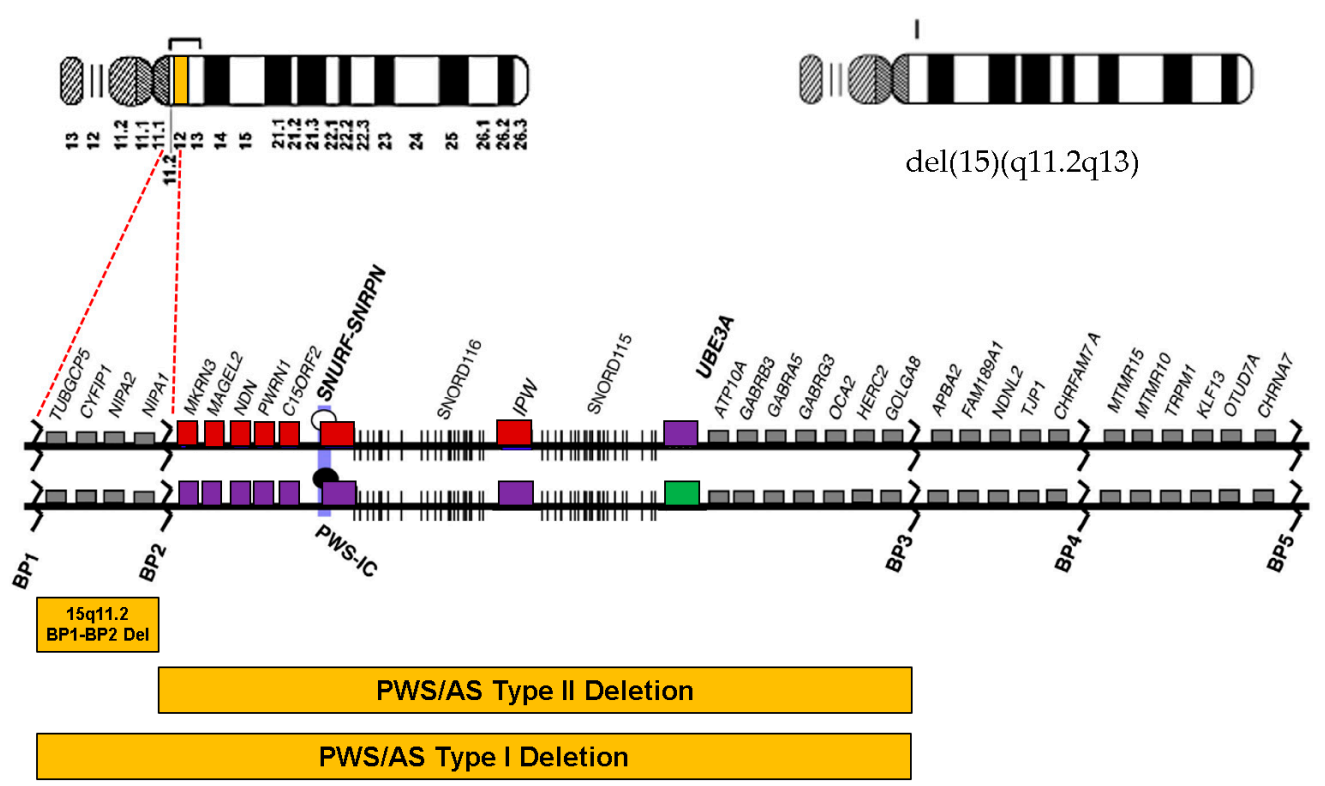

Figure 3. Map of the 15q11.2-q13 region demonstrates gene distribution between breakpoint (BP) 1 and BP5 on the proximal 15q11.2 region. The 15q11.2 deletion region is located between BP1 and BP2. Genes displayed in red and green boxes are imprinted and expressed from the paternal and maternal alleles, respectively. Violet boxes indicate the silenced alleles. Gray boxes mark genes expressed from both parental alleles. Del, deletion; AS, Angelman syndrome; BP, breakpoint; PWS, Prader-Willi syndrome; IC, imprinting center. 


\section{Conclusions}

In conclusion, our three new cases, together with previous findings from the literature review, confirm some of the features earlier reported to be associated with 15q11.2 BP1-BP2 deletion and help to further delineate the phenotype associated with 15q11.2 deletion. Identification of more cases with the 15q11.2 BP1-BP2 deletion will allow us to obtain a better understanding of the clinical phenotypes. Further explanation of the functions of the genes within the $15 q 11.2 \mathrm{BP} 1-\mathrm{BP} 2$ region is required to resolve the pathogenic effects on neurodevelopment.

Author Contributions: Conceptualization, J.Y.H.; data curation, J.Y.H.; formal analysis, J.Y.H. and J.P.; writing—original draft preparation, J.Y.H.; writing—review and editing, J.P.; supervision, J.Y.H. and J.P.; funding acquisition, J.P. All authors have read and agreed to the published version of manuscript.

Funding: This work was supported by the National Research Foundation of Korea (NRF) grant funded by the Korean government (MSIT) (2020R1F1A1077316).

Institutional Review Board Statement: This study protocol was approved by the Institutional Review Board of the Catholic University of Korea (Approval number: DC20ZASI0020; Date of approval: 31 March 2020).

Informed Consent Statement: All subjects provided written informed consent for clinical and molecular analyses and publication before the study.

Data Availability Statement: The data presented in this study are available upon request from the corresponding author.

Conflicts of Interest: The authors declare no conflict of interest.

\section{References}

1. Christian, S.L.; Fantes, J.A.; Mewborn, S.K.; Huang, B.; Ledbetter, D.H. Large genomic duplicons map to sites of instability in the Prader-Willi/Angelman syndrome chromosome region (15q11-q13). Hum. Mol. Genet. 1999, 8, 1025-1037. [CrossRef]

2. Masurel-Paulet, A.; Andrieux, J.; Callier, P.; Cuisset, J.M.; Le Caignec, C.; Holder, M.; Thauvin-Robinet, C.; Doray, B.; Flori, E.; Alex-Cordier, M.P.; et al. Delineation of 15q13.3 microdeletions. Clin. Genet. 2010, 78, 149-161. [CrossRef] [PubMed]

3. Rafi, S.K.; Butler, M.G. The 15q11.2 BP1-BP2 Microdeletion (Burnside-Butler) Syndrome: In Silico Analyses of the Four Coding Genes Reveal Functional Associations with Neurodevelopmental Phenotypes. Int. J. Mol. Sci. 2020, 21, 3296. [CrossRef] [PubMed]

4. Doornbos, M.; Sikkema-Raddatz, B.; Ruijvenkamp, C.A.; Dijkhuizen, T.; Bijlsma, E.K.; Gijsbers, A.C.; Hilhorst-Hofstee, Y.; Hordijk, R.; Verbruggen, K.T.; Kerstjens-Frederikse, W.S.; et al. Nine patients with a microdeletion 15q11.2 between breakpoints 1 and 2 of the Prader-Willi critical region, possibly associated with behavioural disturbances. Eur. J. Med. Genet. 2009, 52, 108-115. [CrossRef] [PubMed]

5. $\quad$ Burnside, R.D.; Pasion, R.; Mikhail, F.M.; Carroll, A.J.; Robin, N.H.; Youngs, E.L.; Gadi, I.K.; Keitges, E.; Jaswaney, V.L.; Papenhausen, P.R.; et al. Microdeletion/microduplication of proximal 15q11.2 between BP1 and BP2: A susceptibility region for neurological dysfunction including developmental and language delay. Hum. Genet. 2011, 130, 517-528. [CrossRef] [PubMed]

6. Abdelmoity, A.T.; LePichon, J.B.; Nyp, S.S.; Soden, S.E.; Daniel, C.A.; Yu, S. 15q11.2 proximal imbalances associated with a diverse array of neuropsychiatric disorders and mild dysmorphic features. J. Dev. Behav. Pediatrics 2012, 33, 570-576. [CrossRef] [PubMed]

7. Vanlerberghe, C.; Petit, F.; Malan, V.; Vincent-Delorme, C.; Bouquillon, S.; Boute, O.; Holder-Espinasse, M.; Delobel, B.; Duban, B.; Vallee, L.; et al. 15q11.2 microdeletion (BP1-BP2) and developmental delay, behaviour issues, epilepsy and congenital heart disease: A series of 52 patients. Eur. J. Med. Genet. 2015, 58, 140-147. [CrossRef]

8. Cox, D.M.; Butler, M.G. The 15q11.2 BP1-BP2 microdeletion syndrome: A review. Int. J. Mol. Sci. 2015, 16, 4068-4082. [CrossRef]

9. Rosenfeld, J.A.; Coe, B.P.; Eichler, E.E.; Cuckle, H.; Shaffer, L.G. Estimates of penetrance for recurrent pathogenic copy-number variations. Genet. Med. Off. J. Am. Coll. Med. Genet. 2013, 15, 478-481. [CrossRef]

10. Richards, S.; Aziz, N.; Bale, S.; Bick, D.; Das, S.; Gastier-Foster, J.; Grody, W.W.; Hegde, M.; Lyon, E.; Spector, E.; et al. Standards and guidelines for the interpretation of sequence variants: A joint consensus recommendation of the American College of Medical Genetics and Genomics and the Association for Molecular Pathology. Genet. Med. Off. J. Am. Coll. Med. Genet. 2015, 17, 405-424. [CrossRef]

11. Saxena, S.; Kkani, P.; Ramasubramanian, C.; Kumar, S.G.; Monisha, R.; Prasad Rao, G.; Mohan, K.N. Analysis of 15q11.2 CNVs in an Indian population with schizophrenia. Ann. Hum. Genet. 2019, 83, 187-191. [CrossRef] [PubMed]

12. Sempere Pérez, A.; Manchón Trives, I.; Palazón Azorín, I.; Alcaraz Más, L.; Pérez Lledó, E.; Galán Sánchez, F. 15Q11.2 (BP1-BP2) microdeletion, a new syndrome with variable expressivity. Anales Pediatria 2011, 75, 58-62. [CrossRef] [PubMed] 
13. Murthy, S.K.; Nygren, A.O.; El Shakankiry, H.M.; Schouten, J.P.; Al Khayat, A.I.; Ridha, A.; Al Ali, M.T. Detection of a novel familial deletion of four genes between BP1 and BP2 of the Prader-Willi/Angelman syndrome critical region by oligo-array CGH in a child with neurological disorder and speech impairment. Cytogenet. Genome Res. 2007, 116, 135-140. [CrossRef]

14. von der Lippe, C.; Rustad, C.; Heimdal, K.; Rodningen, O.K. 15q11.2 microdeletion-Seven new patients with delayed development and/or behavioural problems. Eur. J. Med. Genet. 2011, 54, 357-360. [CrossRef]

15. Madrigal, I.; Rodríguez-Revenga, L.; Xunclà, M.; Milà, M. 15q11.2 microdeletion and FMR1 premutation in a family with intellectual disabilities and autism. Gene 2012, 508, 92-95. [CrossRef] [PubMed]

16. Usrey, K.M.; Williams, C.A.; Dasouki, M.; Fairbrother, L.C.; Butler, M.G. Congenital Arthrogryposis: An Extension of the 15q11.2 BP1-BP2 Microdeletion Syndrome? Case Rep. Genet. 2014, 2014, 127258. [CrossRef]

17. Cooper, G.M.; Coe, B.P.; Girirajan, S.; Rosenfeld, J.A.; Vu, T.H.; Baker, C.; Williams, C.; Stalker, H.; Hamid, R.; Hannig, V.; et al. A copy number variation morbidity map of developmental delay. Nat. Genet. 2011, 43, 838-846. [CrossRef] [PubMed]

18. Cafferkey, M.; Ahn, J.W.; Flinter, F.; Ogilvie, C. Phenotypic features in patients with 15q11.2(BP1-BP2) deletion: Further delineation of an emerging syndrome. Am. J. Med. Genet. Part A 2014, 164, 1916-1922. [CrossRef]

19. Hashemi, B.; Bassett, A.; Chitayat, D.; Chong, K.; Feldman, M.; Flanagan, J.; Goobie, S.; Kawamura, A.; Lowther, C.; Prasad, C.; et al. Deletion of 15q11.2(BP1-BP2) region: Further evidence for lack of phenotypic specificity in a pediatric population. Am. J. Med. Genet. Part A 2015, 167, 2098-2102. [CrossRef] [PubMed]

20. Stefansson, H.; Meyer-Lindenberg, A.; Steinberg, S.; Magnusdottir, B.; Morgen, K.; Arnarsdottir, S.; Bjornsdottir, G.; Walters, G.B.; Jonsdottir, G.A.; Doyle, O.M.; et al. CNVs conferring risk of autism or schizophrenia affect cognition in controls. Nature 2014, 505, 361-366. [CrossRef]

21. Jønch, A.E.; Douard, E.; Moreau, C.; Van Dijck, A.; Passeggeri, M.; Kooy, F.; Puechberty, J.; Campbell, C.; Sanlaville, D.; Lefroy, H.; et al. Estimating the effect size of the 15Q11.2 BP1-BP2 deletion and its contribution to neurodevelopmental symptoms: Recommendations for practice. J. Med. Genet. 2019, 56, 701-710. [CrossRef] [PubMed]

22. van der Meer, D.; Sønderby, I.E.; Kaufmann, T.; Walters, G.B.; Abdellaoui, A.; Ames, D.; Amunts, K.; Andersson, M.; Armstrong, N.J.; Bernard, M.; et al. Association of Copy Number Variation of the 15q11.2 BP1-BP2 Region With Cortical and Subcortical Morphology and Cognition. JAMA Psychiatry 2020, 77, 420-430. [CrossRef] [PubMed]

23. Zhang, D.; Liu, X.; Deng, X. Genetic basis of pediatric epilepsy syndromes. Exp. Med. 2017, 13, 2129-2133. [CrossRef]

24. Wong, D.; Johnson, S.M.; Young, D.; Iwamoto, L.; Sood, S.; Slavin, T.P. Expanding the BP1-BP2 15q11.2 Microdeletion Phenotype: Tracheoesophageal Fistula and Congenital Cataracts. Case Rep. Genet. 2013, 2013, 801094. [CrossRef] [PubMed]

25. Jerkovich, A.M.; Butler, M.G. Further phenotypic expansion of 15q11.2 BP1-BP2 microdeletion (Burnside-Butler) syndrome. J. Pediatric Genet. 2014, 3, 41-44. [CrossRef]

26. Forman, M.; Canizares, M.F.; Bohn, D.; James, M.A.; Samora, J.; Steinman, S.; Wall, L.B.; Bauer, A.S. Association of Radial Longitudinal Deficiency and Thumb Hypoplasia: An Update Using the CoULD Registry. J. Bone Jt. Surg. Am. 2020, 102, 1815-1822. [CrossRef]

27. Pakkasjarvi, N.; Koskimies, E.; Ritvanen, A.; Nietosvaara, Y.; Makitie, O. Characteristics and associated anomalies in radial ray deficiencies in Finland-A population-based study. Am. J. Med. Genet. Part A 2013, 161a, 261-267. [CrossRef]

28. Elmakky, A.; Stanghellini, I.; Landi, A.; Percesepe, A. Role of Genetic Factors in the Pathogenesis of Radial Deficiencies in Humans. Curr. Genom. 2015, 16, 264-278. [CrossRef]

29. Davis, K.W.; Serrano, M.; Loddo, S.; Robinson, C.; Alesi, V.; Dallapiccola, B.; Novelli, A.; Butler, M.G. Parent-of-Origin Effects in 15q11.2 BP1-BP2 Microdeletion (Burnside-Butler) Syndrome. Int. J. Mol. Sci. 2019, 20, 1459. [CrossRef]

30. François, C.; Grabli, D.; McCairn, K.; Jan, C.; Karachi, C.; Hirsch, E.C.; Féger, J.; Tremblay, L. Behavioural disorders induced by external globus pallidus dysfunction in primates II. Anatomical study. Brain J. Neurol. 2004, 127, 2055-2070. [CrossRef]

31. Grabli, D.; McCairn, K.; Hirsch, E.C.; Agid, Y.; Féger, J.; François, C.; Tremblay, L. Behavioural disorders induced by external globus pallidus dysfunction in primates: I. Behavioural study. Brain J. Neurol. 2004, 127, 2039-2054. [CrossRef]

32. Xiong, Y.; Oakley, B.R. In vivo analysis of the functions of gamma-tubulin-complex proteins. J. Cell Sci. 2009, $122,4218-4227$. [CrossRef]

33. Kobayashi, K.; Kuroda, S.; Fukata, M.; Nakamura, T.; Nagase, T.; Nomura, N.; Matsuura, Y.; Yoshida-Kubomura, N.; Iwamatsu, A.; Kaibuchi, K. p140Sra-1 (specifically Rac1-associated protein) is a novel specific target for Rac1 small GTPase. J. Biol. Chem. 1998, 273, 291-295. [CrossRef]

34. Bonaccorso, C.M.; Spatuzza, M.; Di Marco, B.; Gloria, A.; Barrancotto, G.; Cupo, A.; Musumeci, S.A.; D’ Antoni, S.; Bardoni, B.; Catania, M.V. Fragile X mental retardation protein (FMRP) interacting proteins exhibit different expression patterns during development. Int. J. Dev. Neurosci. Off. J. Int. Soc. Dev. Neurosci. 2015, 42, 15-23. [CrossRef] [PubMed]

35. Stewart, L.R.; Hall, A.L.; Kang, S.-H.L.; Shaw, C.A.; Beaudet, A.L. High frequency of known copy number abnormalities and maternal duplication 15q11-q13 in patients with combined schizophrenia and epilepsy. BMC Med. Genet. 2011, 12, 154. [CrossRef] [PubMed]

36. Chai, J.H.; Locke, D.P.; Greally, J.M.; Knoll, J.H.; Ohta, T.; Dunai, J.; Yavor, A.; Eichler, E.E.; Nicholls, R.D. Identification of four highly conserved genes between breakpoint hotspots BP1 and BP2 of the Prader-Willi/Angelman syndromes deletion region that have undergone evolutionary transposition mediated by flanking duplicons. Am. J. Hum. Genet. 2003, 73, 898-925. [CrossRef] [PubMed] 
37. Rainier, S.; Chai, J.H.; Tokarz, D.; Nicholls, R.D.; Fink, J.K. NIPA1 gene mutations cause autosomal dominant hereditary spastic paraplegia (SPG6). Am. J. Hum. Genet. 2003, 73, 967-971. [CrossRef] [PubMed]

38. Chen, S.; Song, C.; Guo, H.; Xu, P.; Huang, W.; Zhou, Y.; Sun, J.; Li, C.X.; Du, Y.; Li, X.; et al. Distinct novel mutations affecting the same base in the NIPA1 gene cause autosomal dominant hereditary spastic paraplegia in two Chinese families. Hum. Mutat. 2005, 25, 135-141. [CrossRef]

39. Butler, M.G. Magnesium Supplement and the 15q11.2 BP1-BP2 Microdeletion (Burnside-Butler) Syndrome: A Potential Treatment? Int. J. Mol. Sci. 2019, 20, 2914. [CrossRef] [PubMed]

40. Jiang, Y.; Zhang, Y.; Zhang, P.; Sang, T.; Zhang, F.; Ji, T.; Huang, Q.; Xie, H.; Du, R.; Cai, B.; et al. NIPA2 located in 15q11.2 is mutated in patients with childhood absence epilepsy. Hum. Genet. 2012, 131, 1217-1224. [CrossRef] [PubMed]

41. Jiang, Y.; Zhang, Y.; Zhang, P.; Zhang, F.; Xie, H.; Chan, P.; Wu, X. NIPA2 mutations are correlative with childhood absence epilepsy in the Han Chinese population. Hum. Genet. 2014, 133, 675-676. [CrossRef] [PubMed]

42. Bray, N.J.; Owen, M.J. A Developmental Perspective on the Convergence of Genetic Risk Factors for Neuropsychiatric Disorders. Biol. Psychiatry 2020, 87, 98-99. [CrossRef] [PubMed]

43. Serdarevic, F.; Tiemeier, H.; Jansen, P.R.; Alemany, S.; Xerxa, Y.; Neumann, A.; Robinson, E.; Hillegers, M.H.J.; Verhulst, F.C.; Ghassabian, A. Polygenic Risk Scores for Developmental Disorders, Neuromotor Functioning During Infancy, and Autistic Traits in Childhood. Biol. Psychiatry 2020, 87, 132-138. [CrossRef] [PubMed] 